\title{
CNC Machine parameter optimisation by BFO-PSO
}

\author{
Nitin* and Amit Kumar \\ JMIT, Radaur, Haryana, India \\ Received 01 March 2018, Accepted 08 May 2018, Available online 10 May 2018, Vol.8, No.3 (May/June 2018)
}

\begin{abstract}
This work talks about decreasing the surface harshness of employments utilized on CNC processing machine. For this reason streamlining calculations are a decision which gives ideal arrangement of estimations of CNC machine parameters which influence the surface harshness amid processing task. The machining of aluminum metal network composites in CNC fast conditions is huge on the grounds that such composites have various applications in the air transportation industry. Since that industry requires amazing results, the expectation of surface harshness, which relies upon input process parameters, accept hugeness in the keeping up nature of items. Frame the writing study it is uncovered that most recent work on this is finished by utilizing gravitational inquiry calculation (GSA) and is contrasted and TLBO, SA and GA (arranged by their execution). The estimations of surface harshness acquired with these are very great however there is dependably extent of change. To get the ideal arrangements of information parameters of CNC machine, a test work done in the paper by Pare V. et.al. is considered as a source of perspective. Their analysis gives a reasonable scope of speed of cutting, profundity of cut, bolster and advance over proportion in which ideal estimations of these can be sought out by our proposed improvement calculation. In this work, we have proposed a half and half calculation by falling bio motivated streamlining calculations: bacterial rummaging enhancement (BFO) and molecule swarm improvement (PSO). For this we have built up the MATLAB content and contrasted the outcomes and the paper. A correlation of results got by BFO-PSO, GSA and TLBO is appeared in our work and half and half calculation enhanced the surface harshness by 13.07\% for direct investigation. The entire examination is directed on the Al2O3 + SiC metal lattice composite.
\end{abstract}

Keywords: Hardness, CNC etc.

\section{Introduction}

Metal cutting innovation, or all the more particularly the machining innovation, is an integral part of any mechanical assembling office. It is additionally considered as the most regularly utilized metal forming process. The size of speculation being made universally in present day machine instruments for doing machining is viewed as a benefit of a country. For the most part, the term metal cutting is characterized as a task in which a thin layer of metal or chip is expelled from a bigger body by utilizing a wedge molded instrument. The term machining can be characterized as a metal cutting procedure in which both the work piece and the device are held firm by a power-driven mechanical structure and the material expelled from the work piece in type of chips is induced by the relative movement amongst device and work piece. Machining innovation discovers its wide based application in a considerable measure of businesses, for instance: car, aviation/air ship and home

*Correspondin author's ORCID ID: 0000-0002-7864-2260 DOI: https://doi.org/10.14741/ijcet/v.8.3.4 apparatuses, to give some examples. The cutting edge history of machining goes back to the finish of the eighteenth century when the instruments made of solidified carbon steel were utilized to machine simple to-cut materials like dark cast iron, metal and bronze, other than basic turning of wood. The machining innovation has advanced from that point onward and in various angles. It has made change in machine apparatus structures, flow, power and firmness. Also, advancement is seen and going ahead in cutting apparatus tip substrates and its coatings; developments in its geometry; in device and workpiece holding gadgets. Advancement in delivering better control (NC and $\mathrm{CNC}$ ) and refined machining programming, for machine apparatus, is delineated in segment 1.2. Machining procedure can be subdivided into following four noteworthy writes, in view of the method of material evacuation.
1) Turning.
2) Drilling.
3) Shaping/Planning.
4) Milling. 
Among the above machining tasks, turning activity is a standout amongst the most broadly and ordinarily utilized cutting activity carried on a machine. A machine in different and diverse structures have been in practice for about over 2000 years. The cutting edge machine dates from around 1797, when Henry Maudsley delivered a machine with a lead screw that gave controlled mechanical nourish of the apparatus . This innovative Englishman likewise developed a changing apparatus framework that was utilized to join the movement of the lead screw. This advancement made it conceivable to cut the string on the machine. Present day machines grew today have speedy change outfit boxes, driven by shaft, that interface the lead screw and sustain bar. The coupled equipping framework, the sustain pole and the lead screw, join the machine instrument carriage to the axle, thus the slicing device can be moved to an exact separation in either transverse or longitudinal course against every pivot of the machine apparatus shaft. Today for the most part current machine machines are numerically controlled. This allows the administrator to make instrument setting and alterations simply by the contribution of numerical information. The instrument can be moved rapidly to the correct position for the following cut, diminishing the measure of machinecontrolling time and expanding the profitability of these robotized expensive machines. An audit of computerization identified with machine device is exhibited in the following area.

\section{Proposed Work}

In this work we worked towards improving the surface roughness of aluminium silicon carbide (Al-SiC) composite using CNC milling machine. Our work is mainly focused on the optimising the machine parameters to get the maximum surface smoothness of job. For this purpose we have picked the necessary values for our experiment from a reference. In the paper they have done experiment on $\mathrm{Al}-\mathrm{SiC}$ composite and recorded four readings of surface roughness depending upon the different sets of machine parameters which affects the surface roughness. This experiment is the base of our research as it gives an allowable range, within which our optimisation gives the tuning parameters' optimal value. A mathematical relationship is developed based on their experiment between surface roughness and optimising parameters if CNC machine. The linear equation which relates the surface roughness with four optimising parameters is given in equation 1

$$
R_{a}=0.893-0.0028 x_{1}+0.00186 x_{2}+1.19 x_{3}+3.39 x_{4}
$$

Where $R_{a}$ is surface roughness in $\mu \mathrm{m}$

$x_{1}$ is speed in $\mathrm{m} / \mathrm{min}$

$x_{2}$ is the feed in $\mu \mathrm{m} / \mathrm{rev}$

$x_{3}$ is the depth of cut $\mathrm{mm}$

$x_{4}$ is the step over ratio
Here these four variant of ' $x$ ' are input parameters if CNC machine whereas surface roughness is the output parameter observed over processed job on CNC. Similarly non linear relation between them is also established which is represented in equation 2 .

$$
\begin{aligned}
& R_{a}=1.99-0.454 \log _{10} x_{1}+0.124 \log _{10} x_{2}+ \\
& 0.157 \log _{10} x_{3}+0.794 \log _{10} x_{4}
\end{aligned}
$$

All notations have same significance as in equation 4.1. To optimise these input variables of CNC machine to get minimum surface roughness, gravitational search algorithm (GSA) has been used previously and tested for teacher learner based optimisation (TLBO) too. Both these algorithms gave comparative results but the convergence time for TLBO is very less than GSA whereas GSA's result is better than TLBO. So in our work we will combine two other optimisation methods to reduce more surface roughness with less convergence time. The combination of two optimisation algorithms can be done in two ways: by mixing them, cascading them. The first one can be used with two different algorithms like one should be local optimisation algorithm and other should be global optimisation algorithm, for example BFO with PSO in which PSO is local optimisation algorithm. In our case we are using BFO and PSO so rather than cascading these are combined by providing control of direction of bacteria to PSO. Now rather than randomly movement of bacteria in each iteration, it will be tuned by PSO and more towards the convergence. Both BFO and PSO are explained in chapter 3. Since these algorithms are optimisation algorithms and can be used in various research fields where providing the solution to any mathematical problem is not easy and problem is NP hard problem, so the significance of terms of used in these changes with every application area. In our case their significance in terms of our CNC machine in tabulated in 1.

Table 1: Technical counterpart of optimisation variables

\begin{tabular}{|c|c|c|}
\hline & $\begin{array}{c}\text { Variable in } \\
\text { BFO/PSO }\end{array}$ & Terms in our technical concept \\
\hline 1 & $\begin{array}{c}\text { Position of } \\
\text { bacteria/particles }\end{array}$ & $\begin{array}{c}\text { Values of four tuning variables: } \\
\text { speed, feed, depth of cut and } \\
\text { step over ratio }\end{array}$ \\
\hline 2 & $\begin{array}{c}\text { Number of } \\
\text { dimension of } \\
\text { searching space }\end{array}$ & $\begin{array}{c}\text { Total number of tuning } \\
\text { variables. In our case it is } 4\end{array}$ \\
\hline 3 & $\begin{array}{c}\text { Update in } \\
\text { positions }\end{array}$ & $\begin{array}{c}\text { Change in the values of above } \\
\text { four parameters }\end{array}$ \\
\hline
\end{tabular}

In both algorithms number of bacteria or particle is set by the user and each bacteria's position is represented by the values of four tuning parameters in a provided search space. In each iteration an objective function is evaluated which is based upon equation 4.1 and 4.2 and this objective function is called every time in each iteration and for every agent/learner. The minimum of all objective function values calculated for all 
agents/learners in each iteration is saved and updated by process defined in BFO and PSO. In next iteration this updated value will be the current values of four tuning parameters and again objective function is called for every agent/learner and minimum value amongst all is saved again. This process keeps on repeating till last iteration. At the end, tuning variables' values for which surface roughness settles to a minimum value in all iterations is considered as the final set of variables. The step by step algorithm is discussed below:

STEP1. Initialize the upper and lower range of speed, feed, depth of cut and step over ratio of CNC machine

\section{BFO starts here}

STEP2. Initialize the random positions and directions of bacteria.

STEP3. Consider the searching space dimension as number of tuning variables which is 4 as described above.

STEP4. Initialize the chemotactic, swarming, reproduction and dispersion steps. The initial step size of bacteria is taken as 0.1 .

STEP5. Initialize the weighting parameters of PSO as 1.2 and 0.5 .

STEP6. In each chemotactic step, for every bacteria fitness function is evaluated (fitness function is discussed in next column) and position of bacteria is updated by position updation formula defined in previous chapter. It is

$$
\begin{aligned}
\text { newpos }=\text { oldpos } & + \text { stepsize } \\
& \times \frac{\text { direction }}{\sqrt{\text { direction } * \text { direction }}}
\end{aligned}
$$

STEP7. In swarming step the previous fitness function output is compared with the next position output of same bacteria. If found less then position of bacetria is updated again by formula given in step 5 .

STEP8. The present position of bacteria is termed as current position of particle for PSO and output of fitness function is Jlocal for the PSO.

\section{PSO Starts here:}

STEP9. Take out the minimum value index from the J local and corresponding bacteria's position is termed as the local best position of particle for each bacteria.

STEP10. The velocity of each particle is further updated from random initial velocity to a PSO tuned velocity by using the formula: newvelocity $=0.9 *$ oldvelocity $+c 1$

$$
\begin{aligned}
& * R 1 \text { (localbestposition } \\
& - \text { currentposiiton) }+c 2 \\
& * \text { R2(globalbestposition } \\
& - \text { currentposititon) }
\end{aligned}
$$

Where $\mathrm{c} 1, \mathrm{c} 2$ and R1,R2 are initialized initially.

STEP11. This new velocity is the direction of bacteria in $\mathrm{BFO}$ as

$$
\text { direction }=\text { velocity }
$$

\section{PSO ends here}

STEP12. The chemotactic and swarming loop continues till all initialized steps are completed. In each loop PSO updates the direction of bacteria and move the bacteria into the direction of fast convergence.

STEP13. Reproduction steps take place for bacteria with high fitness function values.

STEP14. To disperse or kill the weak bacteria, a probability of 0.25 is defined as the deciding probability. If random probability is higher than it, bacteria is dispersed or vice versa.

STEP15. Result will be positions of bacteria with minimum fitness function output. These positions are speed, feed, depth of cut and step over ratio of CNC machine.

\section{BFO ends here}

STEP16. The MATLAB script for objective function used in it is shown in table 2.

Table 2: MATLAB script for objective function

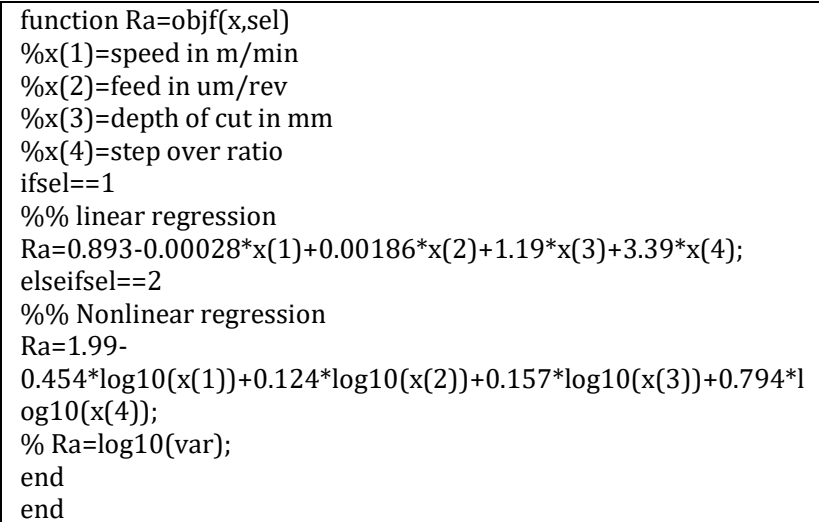

\section{Conclusion}

This work is targeting the optimisation of milling machine parameters to get minimum surface roughness. To achieve this hybrid BFO-PSO optimisation algorithm is used in which we mixedBFO and PSO, the randomness of the direction of bacteria in BFO is tuned by PSO to move the bacteria towards convergence. Four parameters speed of cut, depth of cut, feed rate and step over ratio are the independent variables which affects the dependent surface roughness. So a linear and non linear relationship in between these independent and dependent variables is set and optimised to have minimum surface roughness. In this work we compared both linear and non linear analysis by our proposed optimisation. Non linear relation between variables is giving very less surface roughness. An improvement of $86.75 \%$ over single GSA result in paper, by our method is achieved for non linear relation whereas in case of linear this improvement is $13 \%$. But hybrid BFO-PSO is performing well than single GSA and TLBO in both cases. We have developed our script for all these optimisations and even then these are giving better 
results than paper. This optimisation of variables reduces the hassle to test the job for different set of parameters which also waste the material.So by our proposed optimisation, a very high smoothness of job can be achieved.

\section{Future Scope}

1) Our work can be a basis of number of independent parameters considered for the minimisation of surface roughness.

2) Results obtained and four tuning variables set must be validated on CNC machine which can prove the optimisation results more realistic.

3) Another optimisation approach which is latest like PeSOA can also be combined with GSA or TLBO and tested for more accurate results.

4) There is a scope to consider more such composite materials with various combinations of constituent materials under high-speed cutting conditions in order to compute the optimum values of input machining conditions for better design of manufacturing processes

\section{References}

C. Manikandan, B. Rajeswari (July 2013) Cutting Parameters On Drilling EN24 Using Taguchi Method International Journal of Engineering Research \& Technology (IJERT)

SrinivasaReddy,S. Suresh, F. Anand Raju, A. Gurunadham (Feb 2014) Determination of Optimum Parameters in CNC Drilling of Aluminium Alloy Al6463 by Taguchi Method International Journal of Engineering Research \& Technology (IJERT-)

Nabeel Kadim Abid Al-Sahib, Hasan Fahad Abdulrazzaq (2014)Tool Path Optimization of Drilling Sequence in CNC Machine Using Genetic Algorithm Innovative Systems Design and Engineering

Nakandhrakumar R S (Feb 2015) Adaptive Optimization using Grey Relational Analysis and PID Control of CNC Drilling ProcessInternational Conference on Robotics, Automation, Control and Embedded Systems

Kunal Sharma, Mr. AbhishekJatav (Aug 2015) Optimization of Machining Parameters in Drilling of Stainless Steel International Journal of Scientific Research Engineering \& Technology (IJSRET)
Krupal Pawar and R. D. Palhade (2015) Multi-objective Optimization of CNC Turning Process Parameters for High Speed Steel (M2) Using Taguchi and ANOVA Method International Journal of Hybrid Information Technology

K.G.Durga Prasad, M.V.Prasad and K.Venkata Subbaiah (Jun2015) Optimization of Process Parameters in CNC End Milling of Glass - Fibre Reinforced Plastic International Journal For Research In Emerging Science And Technology

H. Abdullah, R. Ramli, D. A. Wahab, J. A. Qudeiri (June 2015 Simulation Approach Of Cutting Tool Movement Using Artificial Intelligence Method Journal of Engineering Science and Technology

Khashayar Danesh Narooei (Jan 2014) Tool Path Optimization for Drilling Process by CNC Milling Machine Using Ant Colony Optimization (ACO)

Vikas Pare, Geeta Agnihotri, Chimata Krishna (2015)Selection of Optimum Process Parameters in High Speed CNC End-Milling of Composite Materials Using Meta Heuristic Techniques Journal of Mechanical Engineering

N.V.Mahesh Babu Talupula (Jan 2015) Experimental Investigation Ofoptimal Machining Parameters Of Mild Steel In Cnc Milling Using Particle Swarm Optimization IPASJ International Journal of Computer Science (IIJCS)

R. Venkata Rao (Jan 2016), Review of applications of TLBO algorithm and a tutorial for beginners to solve the unconstrained and constrained optimization problems, Decision Science Letters 5(1)

R. Venkata Rao, Vivek Patel (June 2013),An improved teaching-learning-based optimization algorithm for solving unconstrained optimization problems,ScientiaIranica Volume 20, Issue

Baghlani, M. H. Makiabadi,Teaching-Learning-Based Optimization Algorithm For Shape And Size Optimization of Truss Structures With Dynamic Frequency Constraints, IJST, Transactions of Civil Engineering, Vol. 37, pp 409-421

Kai-Lin Wang, Hui-Bin Wang, Li-Xia Yu , Xue-Yu Ma , YunSheng Xue,Toward Teaching-Learning-Based Optimization Algorithm for Dealing with Real-Parameter Optimization Problems, Proceedings of the 2nd International Conference on Computer Science and Electronics Engineering (ICCSEE 2013)

Degarmo E. P., Black J. T., Kosher R. A. (1999), Material Processing in Manufacturing, 8th edition, upper saddle river, NJ, Prentice Hall. 